\title{
GCU
}

Glasgow Caledonian

University

University for the Common Good

\section{Is loneliness a predictor of the modern geriatric giants? Analysis from the survey of health, ageing, and retirement in Europe}

Gine-Garriga, Maria; Jerez-Roig, Javier ; Coll-Planas, Laura; Skelton, Dawn A.; Inzitari, Marco; Booth, Joanne; Souza, Dyego L.B.

Published in:

Maturitas

DOI:

10.1016/j.maturitas.2020.11.010

Publication date:

2021

Document Version

Author accepted manuscript

Link to publication in ResearchOnline

Citation for published version (Harvard):

Gine-Garriga, M, Jerez-Roig, J, Coll-Planas, L, Skelton, DA, Inzitari, M, Booth, J \& Souza, DLB 2021, 'Is loneliness a predictor of the modern geriatric giants? Analysis from the survey of health, ageing, and retirement in Europe', Maturitas, vol. 144, pp. 93-101. https://doi.org/10.1016/j.maturitas.2020.11.010

\section{General rights}

Copyright and moral rights for the publications made accessible in the public portal are retained by the authors and/or other copyright owners and it is a condition of accessing publications that users recognise and abide by the legal requirements associated with these rights.

Take down policy

If you believe that this document breaches copyright please view our takedown policy at https://edshare.gcu.ac.uk/id/eprint/5179 for details of how to contact us. 
Is loneliness a predictor of the modern Geriatric Giants? Analysis from the Survey of Health, Ageing, and Retirement in Europe

Maria Giné-Garriga ${ }^{1,2}$, Javier Jerez-Roig ${ }^{3}$, Laura Coll-Planas ${ }^{4}$, Dawn A. Skelton ${ }^{5}$, Marco Inzitari ${ }^{6,7}$, Joanne Booth ${ }^{5}$, Dyego L. B. Souza ${ }^{8}$

1 Department of Physical Activity and Sport Sciences, Faculty of Psychology, Education and Sport Sciences (FPCEE) Blanquerna, Ramon Llull University, Barcelona, Spain

2 Department of Physiotherapy, Faculty of Health Sciences Blanquerna, Ramon Llull University, Barcelona, Spain.

3 Research group on Methodology, Methods, Models and Outcome of Health and Social Sciences $\left(\mathrm{M}_{3} \mathrm{O}\right)$, Faculty of Health Sciences and Welfare, University of Vic - Central University of Catalonia (UVIC-UCC), 08500 Vic, Spain

4 Fundació Salut i Envelliment (Foundation on Health and Ageing), Universitat Autònoma de Barcelona, Barcelona, Spain

5 Centre for Living, School of Health and Life Sciences, Glasgow Caledonian University, Cowcaddens Road, Glasgow G4 OBA, UK

6 Intermediate Care Hospital, Parc Sanitari Pere Virgili, Avinguda de Vallcarca 169-205, 08023 Barcelona, Spain

7 RE-FiT Barcelona Research Group, Vall d'Hebrón Institute of Research (VHIR), Passeig de la Vall d'Hebron 119-129, 08035 Barcelona, Spain

8 Federal University of Rio Grande do Norte, Department of Collective Health, Postgraduate Programme in Collective Health, Natal, Brazil

Corresponding author: Javier Jerez-Roig, Research group on Methodology, Methods, Models and Outcomes of Health and Social Sciences $\left(\mathrm{M}_{3} \mathrm{O}\right)$. Faculty of Health Sciences and Welfare. Centre for Health and Social Care Research (CESS). University of Vic-Central University of Catalonia (UVic-UCC), e-mail: javier.jerez@uvic.cat, +34938816025, C. Sagrada Família, 7, 08500 Vic, Spain. 


\section{Abstract}

Background. Modern geriatric giants have evolved to encompass four new syndromes of frailty (linked to fatigue and physical inactivity), sarcopenia, anorexia of ageing, and cognitive impairment. In parallel, loneliness has been established as a risk factor for adverse mental and physical health outcomes among older adults.

Objective. To analyse loneliness as a predictor of the modern geriatric giants in European older adults, using a longitudinal design of nationally representative data.

Design. Longitudinal population-based cohort study.

Subjects. Data from countries that participated in waves 5 and 6 of the Survey of Health, Ageing, and Retirement in Europe project. Subsamples according to reported loneliness were 17,742 (for physical inactivity) to 24,524 (for anorexia of ageing).

Methods. Loneliness (measured from wave 5) was the independent variable of interest. The dependent variables were incidence of fatigue, physical inactivity, sarcopenia, anorexia of ageing, and cognitive impairment from wave 5 (baseline) to wave 6 . Poisson regression models were used for multivariable analysis, obtaining Relative Risk (RR) and 95\% confidence intervals (Cl).

Results. The prevalence of loneliness ranged from $9.2 \%$ to $12.4 \%$ at wave 5 . The 2 -year incidence of fatigue was $16 \%$ (95\% Cl: 15.5-16.5), physical inactivity $9.8 \%$ (95\% Cl: 9.4-10.3), sarcopenia 5.6\% (95\% Cl: 5.3-5.9), anorexia of aging was 5.4\% (95\% Cl: 5.1-5.7), and cognitive impairment 10.3\% (95\% Cl: 9.9-10.8). The multivariable analysis showed that loneliness was a predictive factor for fatigue $(30 \%, \mathrm{Cl}: 17-45 \%$ higher risk), physical inactivity (24\%, Cl: $7-43 \%$ higher risk) and cognitive impairment (26\%, Cl: 9-46\% higher risk), adjusted by age, sex, number of chronic diseases, education level, region and depression.

Conclusions. Loneliness is an independent risk factor for fatigue, physical inactivity, and cognitive impairment in older adults. The incidence of anorexia of ageing and sarcopenia was not associated to loneliness during the 2-year observation period.

\section{Keywords:}

Cohort studies, loneliness; modern geriatric giants; SHARE. 


\section{Key points:}

- Loneliness is an independent risk factor for fatigue, physical inactivity and cognitive impairment in European older adults.

- The incidence of anorexia of ageing and sarcopenia was not associated to loneliness during the 2-year observation period.

- These conclusions should inform the design of interventions to target loneliness if fatigue, physical activity and cognitive impairment are to be improved in the older adult population. 


\section{Introduction}

In 1965, Bernard Isaacs coined the term "Geriatric Giants" to describe the conditions of immobility, instability, incontinence, and impaired intellect/memory [1]. Similarly, the Geriatric 5Ms were proposed in 2017 by Mary Tinetti as a simple construct to define core competencies of geriatric medicine, including mind, mobility, medications, multi-complexity and matters most (e.g. shared goals of care), although incontinence was excluded from the model [2]. Modern geriatric giants have evolved over the past 50 years to encompass four new syndromes of frailty, sarcopenia, anorexia of ageing, together with cognitive impairment (impaired intellect according to Isaacs) [3]. These syndromes are risk factors of falls, hip fractures, affective disorders and delirium, with associated increases in morbidity and mortality [3]. Overall, the modern geriatric giants are associated with high costs for health and social care systems. Their presence increases the risk for hospitalisation and cost of care during hospitalisation [4].

If we focus on the modern geriatric giants, a person may have a frailty phenotype when three or more of the following criteria are present: unintentional weight loss, self-reported exhaustion (e.g. fatigue), weakness, slow walking speed, and low levels of physical activity [5]. Unintentional weight loss is highly correlated to anorexia of aging, defined as the loss of appetite and/or decreased food intake in late life. Similarly, weakness is closely related to sarcopenia. In the revised guidelines of the European Working Group on Sarcopenia in Older People [6], muscle strength comes to the forefront of the definition of sarcopenia as it is recognised that strength is better than muscle mass in predicting loss of ability to perform activities of daily living $[7,8]$.

Many risk factors had been associated with anorexia of ageing, such as physical function impairment, social and environmental conditions, as well as acute and chronic diseases [9]. Sarcopenia is a progressive and generalised skeletal muscle disorder that is associated with increased likelihood of adverse outcomes including falls, fractures, ability to perform activities of daily living, physical disability and mortality [10]. Sarcopenia is also associated with cognitive impairment [11], and contributes to lowered quality of life and loss of independence [12].

Mild cognitive impairment $(\mathrm{MCl})$ starts as a syndrome defined as cognitive decline greater than expected for an individual's age and education level, but without impairments in the individual's functional abilities. Individuals with $\mathrm{MCl}$ are more than twice as prone to develop dementia in the future [13]. Available evidence indicates that the prevalence of $\mathrm{MCl}$ ranges 
from $7.7 \%$ to $42.0 \%$ depending on the age group, the country where the study was conducted, and the diagnostic criteria used [13]. Increasing age is the strongest risk factor for cognitive impairment, along with other chronic conditions (e.g. diabetes, high blood pressure), depression, insufficient physical activity, low educational level, and infrequent participation in mentally or socially stimulating activities [14].

Loneliness had been defined as a subjective feeling of limited or lost companionship or social support [15]. Loneliness is a condition in which an individual perceives himself or herself to be socially isolated even when among other people. Loneliness is present over the lifespan but increases with the experience of growing old due to reduced social interactions - particularly with family, friends, and community networks - caused by their retirement, physical changes (cognitive and physical disabilities), loss of peers - spouse and friends- (shrinking network size), and/or living alone or in institutions [15].

Loneliness has been established as a risk factor for the adverse mental and physical health events among older adults $[15,16]$, more prone to leading to depression and dementia [17], a higher level of cognitive and physical disability [18], and increased mortality [15]. Loneliness is significantly and negatively correlated with cognitive function in several studies [19]. According to one meta-analysis [20], adults with adequate or strong social relationships had a $50 \%$ increased likelihood of survival compared with those with weaker or insufficient relationships. A recent study showed that frail older adults were at increased risk of mortality, but this risk was even higher for those who were also lonely [21]. Loneliness is emerging as a public health issue [22], and is associated with a $26 \%$ increase in the risk of premature mortality [23].

Therefore, our main aim was to analyse loneliness as a predictor of the modern geriatric giants (frailty -linked to fatigue and physical inactivity-, sarcopenia, anorexia of ageing, and cognitive impairment) in European older adults, using longitudinal population-based representative data.

\section{Methods}

We present a longitudinal population-based cohort study using data from waves 5 and 6 of the Survey of Health, Ageing, and Retirement in Europe (SHARE) project (www.share-project.org). The aforementioned study is the largest multidisciplinary, cross-country, longitudinal research project conducted in Europe. The SHARE Project respects the Helsinki Declaration, in terms of anonymity of the participants and obtaining of written consent. Wave 4 and following waves 
have been reviewed and approved by the Ethics Committee of the Max Planck Society. Furthermore, individual country implementation of SHARE was reviewed and approved by the respective ethics committees or institutional review boards. Further details about data collection, sampling procedures and other methodological aspects are available in the project's website (www.share-project.org) [24].

Data from 16 European countries that participated in waves 5 and 6 were considered: Austria, Germany, Sweden, Netherlands, Spain, Italy, France, Denmark, Switzerland, Belgium, Israel, Czech Republic, Poland, Luxemburg, Slovenia and Estonia. Due to data incompleteness, the subsample was reduced to 10 countries (Austria, Germany, Sweden, Spain, Italy, France, Denmark, Switzerland, Belgium and Czech Republic) for the analysis of physical inactivity and cognitive impairment. Although sampling differed slightly, all countries obtained probability samples [25]. The smallest proportion difference found in the outcomes was $3 \%$ in anorexia of ageing, between the group with and without loneliness. From this difference in proportion, it would be possible to estimate a significant relative risk, at a $95 \%$ confidence level and a $90 \%$ test power, with a sample of 1071 individuals in each group (exposed and not exposed to loneliness) [26].

The main inclusion criterion was being 65 years and older. Cases with incomplete data on age and loneliness were excluded from this study (see figure 1). Individuals that presented the outcome (fatigue, physical inactivity, sarcopenia, anorexia of ageing, and cognitive impairment) at baseline (wave 5) were also excluded from the analysis. The dependent variables were incidence of fatigue, physical inactivity, sarcopenia, anorexia of ageing, and cognitive impairment from wave 5 to 6 . Loneliness as measured at wave 5 was the independent variable of interest. The theoretical model showing the potential causal links explored in the analysis is represented in figure 2.

Figure 2. Theoretical model of potential causal links explored in the analysis.

Loneliness was measured using the short version of the Revised University of California at Los Angeles Loneliness scale (R-UCLA) [27], which is a frequently used and validated indicator of loneliness [28]. The scale was recently harmonised for use in SHARE [29]. While the UCLA scale is among the most internationally applied scales to assess loneliness, few studies have used the R-UCLA in a cross-national context [30]. It includes the following three questions: how much of the time do you feel a lack of companionship; how much of the time do you feel left 
out; and how much of the time do you feel isolated from others. The answers are recorded using three categories: often, some of the time, hardly ever/never. These items form a scale that ranges from three to nine, whereby three corresponds to not feeling lonely and nine indicates the highest level of loneliness. Therefore, we converted it to a binary measure. We defined those who fell into the first, second and third quartiles as "not lonely" and those in the fourth quartile as "lonely", similar to the method used by Niedzwiedz (2016) [30]. Our analysis used a dichotomous measure of loneliness because we believed each item in the scale better represented different ways a person might express loneliness rather than additive components of loneliness.

Fatigue was identified from the question on frailty symptoms: "for the past six months at least, have you been bothered by any of the health conditions mentioned below?" Among different items, the respondent could choose fatigue. Physical inactivity was defined as 'never or hardly ever engaging in': moderate-intensity activities such as gardening, cleaning the car or going for a walk, or vigorous physical activities such as sports, heavy housework or a job that involves physical labour [31].

Sarcopenia was measured by grip strength, with cut-offs for the continuous variable following the new revised European Consensus on Sarcopenia, e.g. $<27 \mathrm{~kg}$ and $<16 \mathrm{~kg}$ for men and women, respectively [6]. Anorexia of ageing/unintentional weight loss was assessed using the self-reported question: in the last year, have you lost more than (>) $4.5 \mathrm{~kg}$ (10 pounds) or at least $5 \%$ of the previous year's body weight unintentionally (e.g., not due to dieting or more exercising)? Answering 'yes due to health-related issues' (e.g. illness) was considered to represent anorexia of ageing.

The SHARE protocol included performance-based cognitive tests [32]. Performance on verbal fluency is a sensitive measure for discriminating between cognitively healthy individuals and those with $\mathrm{MCl}$ or dementia [33]. Threshold performance scores for being coded as 'yes' (indicating impairment) were set in relation to scores previously shown to be indicative of $\mathrm{MCl}$, as follows: verbal fluency scores $<15.33$.

Other variables included were age (years), sex, educational level and number of chronic diseases. Regarding the last of these, the following conditions were considered: heart attack, hypertension, high blood cholesterol, stroke or cerebral vascular disease, diabetes, chronic lung disease, cancer, Parkinson disease, cataracts, hip fracture, other fractures, dementia, 
affective/emotional disorders (including anxiety, nervous or psychiatric problems) and rheumatoid arthritis/osteoarthritis. The educational level categories from the International Standard Classification of Educational Degrees (ISCED) of 1997 and 2011 were considered [34].

Initially, a descriptive analysis was performed for each sub-sample (fatigue, physical inactivity, sarcopenia, anorexia of ageing and cognitive impairment), indicating absolute and relative frequencies and mean and standard deviation for categorical and continuous variables, respectively. Incidences of the outcomes for the 2-year period and its confidence intervals (Cl) were estimated. Poisson regression models were used for multivariable analysis, obtaining Relative Risk (RR) [35]. To calculate the $\mathrm{Cl}$ at 95\%, the mean - [1.96 x standard deviation (SD)] and the mean $+[1.96 \times \mathrm{SD}]$ were considered for the lower and higher limits, respectively. Multivariaty models were adjusted by age, sex, educational level, number of chronic diseases and depression. Statistical analysis was conducted using Stata (Stata Corp. Inc. TX, USA, version 14).

\section{Results}

Among 68,188 individuals that participated in the SHARE's wave 5, the subsamples selected for each analysis according to reported loneliness were: fatigue 20,237 ; physical inactivity 17,742 ; sarcopenia 20,098; anorexia of ageing 24,524; and cognitive impairment 18,328. Figure 1 shows the process for creating the analytical sample and data set used for analyses. The percentage of missing values for the confounders ranged from $0 \%$ (age, sex, and country) to $4.6 \%$ (depression).

Figure 1. Flow chart of the study sampling process.

The prevalence of loneliness at each subsample ranged from 9.2\% (cognitive impairment) to $12.4 \%$ (anorexia of ageing) at wave 5 , with $9.5 \%$ in the subsample who were physically inactive, $9.6 \%$ in the subsample with fatigue, and $10.9 \%$ in the subsample with sarcopenia. The incidence of fatigue after the 2-year observation period was $16 \%(95 \% \mathrm{Cl}: 15.5-16.5)$, physical inactivity was 9.8\% (95\% Cl: 9.4-10.3), sarcopenia was 5.6\% (95\% Cl: 5.3-5.9), anorexia of ageing was 5.4\% (95\% Cl: 5.1-5.7), and cognitive impairment was 10.3\% (95\% Cl: 9.9-10.8) (figure 3).

Figure 3. Incidence of fatigue, physical inactivity, sarcopenia, anorexia of ageing, and cognitive impairment among older adults during the 2-year period. 
Table 1 describes the sample characteristics for each outcome by dependent variable. Subjects that presented with fatigue, physical inactivity, anorexia of ageing, and cognitive impairment during the period were older, had lower educational level and reported a higher number of chronic diseases. The proportion of women, loneliness and depression was higher among individuals that reported these four outcomes. The same pattern was observed for sarcopenia, except that the proportion of men was slightly higher than for women.

Table 1. Descriptive analysis of the subsamples (according to reported loneliness) for the outcomes fatigue, physical inactivity, sarcopenia, anorexia of ageing, and cognitive impairment in older adults.

The indicators were selected in the multivariable model for each outcome after collinearity tests were carried out and resulted negative. The results of the bivariate and multivariable analysis are shown in Table 2. Loneliness, age, number of chronic diseases, education level and depression were significant predictive factors of fatigue, physical inactivity, sarcopenia, anorexia of ageing, and cognitive impairment in the bivariate analysis. Sex resulted not significant for the prediction of sarcopenia, anorexia of ageing and cognitive impairment, while women presented significantly higher risk of fatigue and physical inactivity. Regarding the multivariable analysis, loneliness was a predictive factor for fatigue $(30 \%, \mathrm{Cl}: 17-45 \%$ higher risk), physical inactivity (24\%, Cl: $7-43 \%$ higher risk) and cognitive impairment (26\%, Cl: 9-46\% higher risk), adjusted by age, sex, number of chronic diseases, education level, region and depression. Loneliness was not included in the models for anorexia of ageing and sarcopenia as it was not significant when tested in the multivariable analysis and did not adjust the final models. Older age, higher number of chronic conditions, lower education level and depression were significant risk factors of all outcomes. Sex was not significant for the incidence of anorexia of ageing and cognitive impairment, while women were at lower risk of developing sarcopenia and at higher risk of fatigue and physical inactivity.

Compared to the Northern European region, the risk of anorexia of ageing was significantly higher at the Eastern region and lower at the Southern. The risk of fatigue was more than two times higher at the Eastern region and Israel while the risk of sarcopenia was significantly higher at the Eastern and Southern regions as well as Israel. The Northern region presented lower risk of being insufficiently active and having cognitive impairment when compared with 
the rest of European regions that presented a higher risk (approximately three times higher in the Southern European countries).

The indicators were selected in the multivariable model for each outcome after collinearity tests were carried out and resulted negative. The bivariate and multivariable analysis (Table 2) shows that loneliness was a predictive factor for fatigue, physical inactivity and cognitive impairment. Figure 4 summarizes the multivariable analysis results based on our theoretical model. The predictive factors for anorexia of ageing were age, chronic diseases, education and depression, adjusted by sex. The predictive factors for fatigue were age, sex, chronic diseases, depression and loneliness, independent of education. Predictive factors for sarcopenia were age, sex, education, chronic diseases and depression. For physical inactivity, the predictive factors were age, sex, education, chronic diseases, depression and loneliness. The predictive factors for cognitive decline were age, sex, education, chronic diseases, depression and loneliness.

Table 2. Final multivariable models of loneliness as a predictor of the outcomes fatigue, physical inactivity, sarcopenia, anorexia of ageing and cognitive impairment in older adults.

Figure 4. Theoretical model summarizing the multivariable analysis results.

\section{Discussion}

This study aimed to assess the associations between loneliness and the modern geriatric giants of frailty (linked to fatigue and physical inactivity) [5], sarcopenia, anorexia of ageing, and cognitive impairment. The results indicate that loneliness is associated to fatigue/ selfreported exhaustion, insufficient physical activity, and cognitive impairment, including age, sex, number of chronic conditions, educational background and depression as confounder variables. However, loneliness was not associated with incident anorexia of ageing/ unintentional weight loss and sarcopenia/ weakness.

Fatigue showed the highest incidence rate in the 2 years follow-up, among the different outcomes taken into account, followed by cognitive impairment, physical inactivity, sarcopenia and anorexia of ageing.

Loneliness is highly prevalent in the population, with $80 \%$ of those under 18 years of age and $40 \%$ of adults over 65 years of age reporting being lonely at least sometimes [36,37]. For as 
many as $15-30 \%$ of the general population, however, loneliness can be a transient or a chronic state, the latter being the most problematic [38]. The prevalence of loneliness in the present study ranged from $9.2 \%$ to $12.4 \%$. Several authors have posited that loneliness is the social equivalent of physical pain, hunger, and thirst; the pain of social disconnection and the hunger and thirst for social connection [39].

In our study, loneliness was found to be a predictor for fatigue/ self-reported exhaustion, insufficient physical activity, and cognitive impairment. Being physically active requires a positive attitude towards voluntary participation, which is enhanced or reduced depending on social and cultural determinants. Compromised regulation of emotion in lonely individuals might explain their diminished likelihood of performing any physical activity, and loneliness has been associated to a decrease in physical activity over time [40]. Likewise, an individual with more social connections, thus more prone to a lower perception of loneliness, may have more occasions to be physically active. Physical activity is a well-known protective factor for physical health, mental health, and cognitive functioning [41], suggesting that poorer selfregulation may contribute to the greater health risk associated with loneliness, via diminished likelihood of engaging in health-promoting behaviors. In clinical populations, lower levels of physical activity have been shown to be related to general feelings of fatigue [42]. In an attempt to avoid excessive fatigue, individuals may reduce their physical activity, which could yield a weak association.

Loneliness has been shown to have a strong association with depression in multiple studies $[39,43]$. Evidence has shown that higher levels of loneliness are consistently associated with higher incidence of depression and elevated depressive symptoms across different age groups [44], even after controlling for socio-demographic factors and other relevant covariates [45]. Findings of prior research among older adults have indicated that loneliness is more hazardous to depression than social isolation [46]. Furthermore, compared to social isolation, loneliness has a much stronger association with depressive symptoms in adults aged 21 and above [47]. Loneliness predicts increases in depressive symptoms over 1-year intervals, but depressive symptoms do not predict increases in loneliness over those same intervals [48]. One of the social and emotional-related symptoms of depression is the feeling of selfexhaustion and perceived fatigue in carrying out usual activities of daily living [49]. Studies highlight the negative impact of self-perceived fatigue on mental and physical health, functional disability and performance restriction in activities of daily living in the older adult population [49], which is in line with our findings. 
The impact of loneliness on cognition was assessed in a recent review of the literature [50]. Loneliness has been associated with impaired cognitive performance and cognitive decline over time [51]. Other studies, however, have indicated that loneliness is a precursor to cognitive impairment. For instance, the cognitive functioning of 75-85-year-olds (as assessed by the Mini-Mental State Examination) did not differ as a function of loneliness at baseline but diminished to a greater extent among those with high rather than low reported loneliness over a 10-year follow-up [52].

As mentioned, fatigue, insufficient physical activity, and cognitive impairment have strong social and emotional components, and so has loneliness. We tend to analyze these outcomes independently yet their interconnections should also be acknowledged. Loneliness had a weak association with anorexia of ageing/ unintentional weight loss and sarcopenia/ weakness, which are physical and functional-related components of frailty [5]. Even though the aforementioned socially-focused outcomes are strongly associated with the functional-related components of frailty, we only analyzed the data over a two-year period, and therefore could have missed changes that require a longer period of time to become evident [53]. These two variables showed the lowest incidence rate in wave 6 , suggesting that they not only were not present at baseline (wave 5) but that we would need more time to show a higher incidence, as they both worsen with age [53].

Studies show that once social and emotional-related health problems appear, it takes some time for effects to show on physical-related conditions, such as a decline in functional performance [53]. Being physically active might act as a mediator which requires a voluntarily action to being able to have an impact (if practiced with sufficient dose, intensity and frequency) on physical function in the longer term [54].

The present study has some limitations; most of the outcomes of the SHARE survey are selfreported, which could have biased our results. It is worth commenting that gait speed, which is also an indicator of physical frailty [5], could not be included in the analysis due to $>80 \%$ missing values in the included waves. The same limitation was also found in cognitive variables such as the self-reported memory item and the memory performance task (e.g. assesses ability to immediately recall as many words as possible) in wave 6 . There seems likely to be other relevant potential confounders that have not been included in the present model (e.g. 
income). There is no single best indicator of socio economic status suitable for all study aims and applicable at all time points in all settings. Education is comparatively easy to measure in self-administered questionnaires, garners a high response rate, and is relevant to people regardless of age, unlike many other socio economic indicators [55]. In contrast, this study has strength in the high-quality data set and sample size with sufficient precision of estimates.

It can be concluded that loneliness is an independent risk factor for fatigue, physical inactivity, and cognitive impairment in older adults. Anorexia of ageing/ unintentional weight loss and sarcopenia/ weakness were not associated to loneliness during the 2-year observation period. However, future longitudinal studies with longer periods are warranted to further analyze the association of loneliness with these physical health-related issues. As far as we know, this is the first study to underline the relevance of loneliness as a predictor of the modern geriatric giants in European older adults by using a longitudinal design of nationally representative data. These conclusions should inform the design of interventions to target loneliness if fatigue, physical activity, and cognitive impairment are to be improved in the older adult population. Relevant confounders that are not commonly reported should also be taken into account when designing interventions to improve loneliness, such as relationship status along with other markers of socio-economic status.

\section{References}

1. Isaacs, B. A giant of geriatric medicine. In: British Geriatrics Society, 1995. http://www.bgs.org.uk/geriatricmedicinearchive/bgsarchive/biographies/a-giant-ofgeriatric-medicine-professor-bernard-isaacs-1924-1995.

2. Tinetti M, Huang A, Molnar F. The Geriatrics 5M's: A New Way of Communicating What We Do. J Am Geriatr Soc. 2017;65(9):2115-2115. doi:10.1111/jgs.14979

3. Morley JE. The New Geriatric Giants. Clin Geriatr Med. 2017;33(3):xi-xii. doi:10.1016/j.cger.2017.05.001

4. Cawthon PM, Lui L-Y, Taylor BC, et al. Clinical Definitions of Sarcopenia and Risk of Hospitalization in Community-Dwelling Older Men: The Osteoporotic Fractures in Men Study. Journals Gerontol Ser A. 2017;72(10):1383-1389. doi:10.1093/gerona/glw327

5. Fried LP, Tangen CM, Walston J, et al. Frailty in Older Adults: Evidence for a Phenotype. Journals Gerontol Ser A Biol Sci Med Sci. 2001;56(3):M146-M157. doi:10.1093/gerona/56.3.M146

6. Cruz-Jentoft AJ, Bahat G, Bauer J, et al. Sarcopenia: revised European consensus on 
definition and diagnosis. Age Ageing. 2019;48(4):601-601. doi:10.1093/ageing/afz046

7. McGregor RA, Cameron-Smith D, Poppitt SD. It is not just muscle mass: a review of muscle quality, composition and metabolism during ageing as determinants of muscle function and mobility in later life. Longev Heal. 2014;3(1):9. doi:10.1186/2046-2395-3-9

8. Schaap LA, van Schoor NM, Lips P, Visser M. Associations of Sarcopenia Definitions, and Their Components, With the Incidence of Recurrent Falling and Fractures: The Longitudinal Aging Study Amsterdam. Journals Gerontol Ser A. 2018;73(9):1199-1204. doi:10.1093/gerona/g|x245

9. Landi F, Lattanzio F, Dell'Aquila G, et al. Prevalence and Potentially Reversible Factors Associated With Anorexia Among Older Nursing Home Residents: Results from the ULISSE Project. J Am Med Dir Assoc. 2013;14(2):119-124. doi:10.1016/j.jamda.2012.10.022

10. Malmstrom TK, Miller DK, Simonsick EM, Ferrucci L, Morley JE. SARC-F: a symptom score to predict persons with sarcopenia at risk for poor functional outcomes. J Cachexia Sarcopenia Muscle. 2016;7(1):28-36. doi:10.1002/jcsm.12048

11. Chang K-V, Hsu T-H, Wu W-T, Huang K-C, Han D-S. Association Between Sarcopenia and Cognitive Impairment: A Systematic Review and Meta-Analysis. J Am Med Dir Assoc. 2016;17(12):1164.e7-1164.e15. doi:10.1016/j.jamda.2016.09.013

12. Beaudart C, Biver E, Reginster J-Y, et al. Validation of the SarQo $L^{\circledR}$, a specific healthrelated quality of life questionnaire for Sarcopenia. J Cachexia Sarcopenia Muscle. 2017;8(2):238-244. doi:10.1002/jcsm.12149

13. Tampi RR, Tampi DJ, Chandran S, Ghori A DM. Mild cognitive impairment: A comprehensive review. Heal Aging Res. 2015. doi:10.12715/har.2015.4.39

14. Petersen RC, Roberts RO, Knopman DS, et al. Prevalence of mild cognitive impairment is higher in men: The Mayo Clinic Study of Aging. Neurology. 2010;75(10):889-897. doi:10.1212/WNL.0b013e3181f11d85

15. Cornwell EY, Waite LJ. Social Disconnectedness, Perceived Isolation, and Health among Older Adults. J Health Soc Behav. 2009;50(1):31-48. doi:10.1177/002214650905000103

16. Fiori KL, Smith J, Antonucci TC. Social Network Types Among Older Adults: A Multidimensional Approach. Journals Gerontol Ser B Psychol Sci Soc Sci. 2007;62(6):P322P330. doi:10.1093/geronb/62.6.P322

17. Cacioppo JT, Hawkley LC, Norman GJ, Berntson GG. Social isolation. Ann N Y Acad Sci. 2011;1231(1):17-22. doi:10.1111/j.1749-6632.2011.06028.x

18. Havens B, Hall M, Sylvestre G, Jivan T. Social Isolation and Loneliness: Differences between Older Rural and Urban Manitobans. Can J Aging / La Rev Can du Vieil. 2004;23(2):129-140. doi:10.1353/cja.2004.0022 
19. Lara E, Caballero FF, Rico-Uribe LA, et al. Are loneliness and social isolation associated with cognitive decline? Int J Geriatr Psychiatry. 2019;34(11):1613-1622.

doi:10.1002/gps.5174

20. Holt-Lunstad J, Smith TB, Layton JB. Social Relationships and Mortality Risk: A Metaanalytic Review. Brayne C, ed. PLoS Med. 2010;7(7):e1000316. doi:10.1371/journal.pmed.1000316

21. Hoogendijk EO, Smit AP, Dam C, et al. Frailty Combined with Loneliness or Social Isolation: An Elevated Risk for Mortality in Later Life. J Am Geriatr Soc. July 2020:jgs.16716. doi:10.1111/jgs.16716

22. Cacioppo JT, Cacioppo S. The growing problem of loneliness. Lancet. 2018;391(10119):426. doi:10.1016/S0140-6736(18)30142-9

23. Holt-Lunstad J, Smith TB. Loneliness and social isolation as risk factors for CVD: implications for evidence-based patient care and scientific inquiry. Heart. 2016;102(13):987-989. doi:10.1136/heartjnl-2015-309242

24. SHARE. SHARE. http://www.share-project.org.

25. Börsch-Supan A. Survey of Health, Ageing and Retirement in Europe (SHARE) Wave 6.; 2019. doi:10.6103/SHARE.w6.700

26. Lwanga S, Lemeshow S. Sample Size Determination in Health Studies: A Practical Manual. (World Health Organization, ed.). Geneva; 1991. https://apps.who.int/iris/handle/10665/40062.

27. Hughes ME, Waite LJ, Hawkley LC, Cacioppo JT. A Short Scale for Measuring Loneliness in Large Surveys. Res Aging. 2004;26(6):655-672. doi:10.1177/0164027504268574

28. Boss L, Kang D-H, Branson S. Loneliness and cognitive function in the older adult: a systematic review. Int Psychogeriatrics. 2015;27(4):541-553. doi:10.1017/S1041610214002749

29. Malter, F., Börsch-Supan, A. SHARE Wave 4: Innovations \& Methodology. Munich: MEA, Max Planck Institute for Social Law and Social Policy (2013).

30. Niedzwiedz CL, Richardson EA, Tunstall H, Shortt NK, Mitchell RJ, Pearce JR. The relationship between wealth and loneliness among older people across Europe: Is social participation protective? Prev Med (Baltim). 2016;91:24-31. doi:10.1016/j.ypmed.2016.07.016

31. Wahrendorf M, Reinhardt JD, Siegrist J. Relationships of Disability with Age Among Adults Aged 50 to 85: Evidence from the United States, England and Continental Europe. Zhang H, ed. PLoS One. 2013;8(8):e71893. doi:10.1371/journal.pone.0071893

32. Ofstedal MB, Fisher GG HR. Documentation of Cognitive Functioning Measures in the 
Health and Retirement Study HRS Documentation Report DR-006 [Online].; 2005.

http://hrsonline.isr.umich.edu/sitedocs/userg/dr-006.pdf.

33. Balthazar MLF, Cendes F, Damasceno BP. Category verbal fluency performance may be impaired in amnestic mild cognitive impairment. Dement Neuropsychol. 2007;1(2):161165. doi:10.1590/s1980-57642008dn10200008

34. UNESCO. The International Standard Classification of Education 2011. Montreal, Canada; 2013.

35. Espelt A, Marí-Dell’Olmo M, Penelo E, Bosque-Prous M. Estimación de la Razón de Prevalencia con distintos modelos de Regresión: Ejemplo de un estudio internacional en investigación de las adicciones. Adicciones. 2016;29(2):105. doi:10.20882/adicciones.823

36. Pinquart M, Sorensen S. Influences on Loneliness in Older Adults: A Meta-Analysis. Basic Appl Soc Psych. 2001;23(4):245-266. doi:10.1207/153248301753225702

37. Berguno, G., Leroux, P., McAinsh, K., \& Shaikh S. Children's Experience of Loneliness at School and its Relation to Bullying and the Quality of Teacher Interventions. Qual Rep. 2004;9(3):483-499.

38. Heinrich LM, Gullone E. The clinical significance of loneliness: A literature review. Clin Psychol Rev. 2006;26(6):695-718. doi:10.1016/j.cpr.2006.04.002

39. Chou K-L, Liang K, Sareen J. The Association Between Social Isolation and DSM-IV Mood, Anxiety, and Substance Use Disorders. J Clin Psychiatry. 2011;72(11):1468-1476. doi:10.4088/JCP.10m06019gry

40. Hawkley LC, Thisted RA, Cacioppo JT. Loneliness predicts reduced physical activity: Crosssectional \&amp; longitudinal analyses. Heal Psychol. 2009;28(3):354-363. doi:10.1037/a0014400

41. Warburton DER. Health benefits of physical activity: the evidence. Can Med Assoc J. 2006;174(6):801-809. doi:10.1503/cmaj.051351

42. Christie AD, Seery E, Kent JA. Physical activity, sleep quality, and self-reported fatigue across the adult lifespan. Exp Gerontol. 2016;77:7-11. doi:10.1016/j.exger.2016.02.001

43. Cacioppo JT, Hughes ME, Waite LJ, Hawkley LC, Thisted RA. Loneliness as a specific risk factor for depressive symptoms: Cross-sectional and longitudinal analyses. Psychol Aging. 2006;21(1):140-151. doi:10.1037/0882-7974.21.1.140

44. Victor CR, Yang K. The Prevalence of Loneliness Among Adults: A Case Study of the United Kingdom. J Psychol. 2012;146(1-2):85-104. doi:10.1080/00223980.2011.613875

45. Adams KB, Sanders S, Auth EA. Loneliness and depression in independent living retirement communities: risk and resilience factors. Aging Ment Health. 2004;8(6):475485. doi:10.1080/13607860410001725054 
46. Miller G. Why Loneliness Is Hazardous to Your Health. Science (80- ). 2011;331(6014):138140. doi:10.1126/science.331.6014.138

47. Ge L, Yap CW, Ong R, Heng BH. Social isolation, loneliness and their relationships with depressive symptoms: A population-based study. Khan HTA, ed. PLoS One. 2017;12(8):e0182145. doi:10.1371/journal.pone.0182145

48. Cacioppo JT, Hawkley LC, Thisted RA. Perceived social isolation makes me sad: 5-year cross-lagged analyses of loneliness and depressive symptomatology in the Chicago Health, Aging, and Social Relations Study. Psychol Aging. 2010;25(2):453-463. doi:10.1037/a0017216

49. Vestergaard S, Nayfield SG, Patel K V., et al. Fatigue in a Representative Population of Older Persons and Its Association With Functional Impairment, Functional Limitation, and Disability. Journals Gerontol Ser A Biol Sci Med Sci. 2009;64A(1):76-82. doi:10.1093/gerona/gln017

50. Cacioppo JT, Hawkley LC. Perceived social isolation and cognition. Trends Cogn Sci. 2009;13(10):447-454. doi:10.1016/j.tics.2009.06.005

51. Sundström A, Nordin Adolfsson A, Nordin M, Adolfsson R. Loneliness increases the risk of all-cause dementia and Alzheimer's disease. Journals Gerontol Ser B. October 2019. doi:10.1093/geronb/gbz139

52. Tilvis RS, Kahonen-Vare MH, Jolkkonen J, Valvanne J, Pitkala KH, Strandberg TE. Predictors of Cognitive Decline and Mortality of Aged People Over a 10-Year Period. Journals Gerontol Ser A Biol Sci Med Sci. 2004;59(3):M268-M274. doi:10.1093/gerona/59.3.M268

53. Jonkman NH, Del Panta V, Hoekstra T, et al. Predicting Trajectories of Functional Decline in 60- to 70-Year-Old People. Gerontology. 2018;64(3):212-221. doi:10.1159/000485135

54. Langhammer B, Bergland A, Rydwik E. The Importance of Physical Activity Exercise among Older People. Biomed Res Int. 2018;2018:1-3. doi:10.1155/2018/7856823

55. Galobardes B. Indicators of socioeconomic position (part 1). J Epidemiol Community Heal. 2006;60(1):7-12. doi:10.1136/jech.2004.023531 


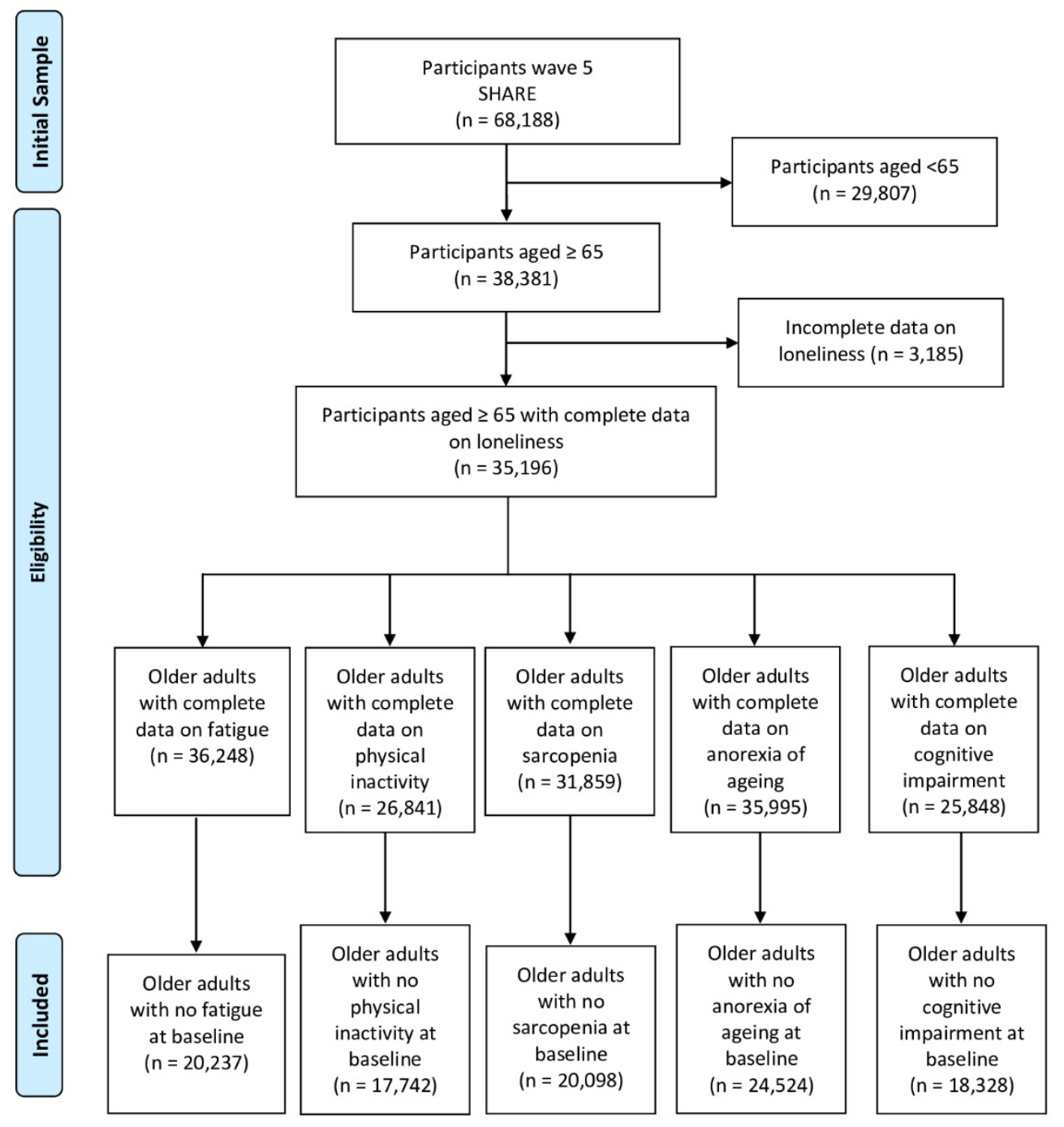




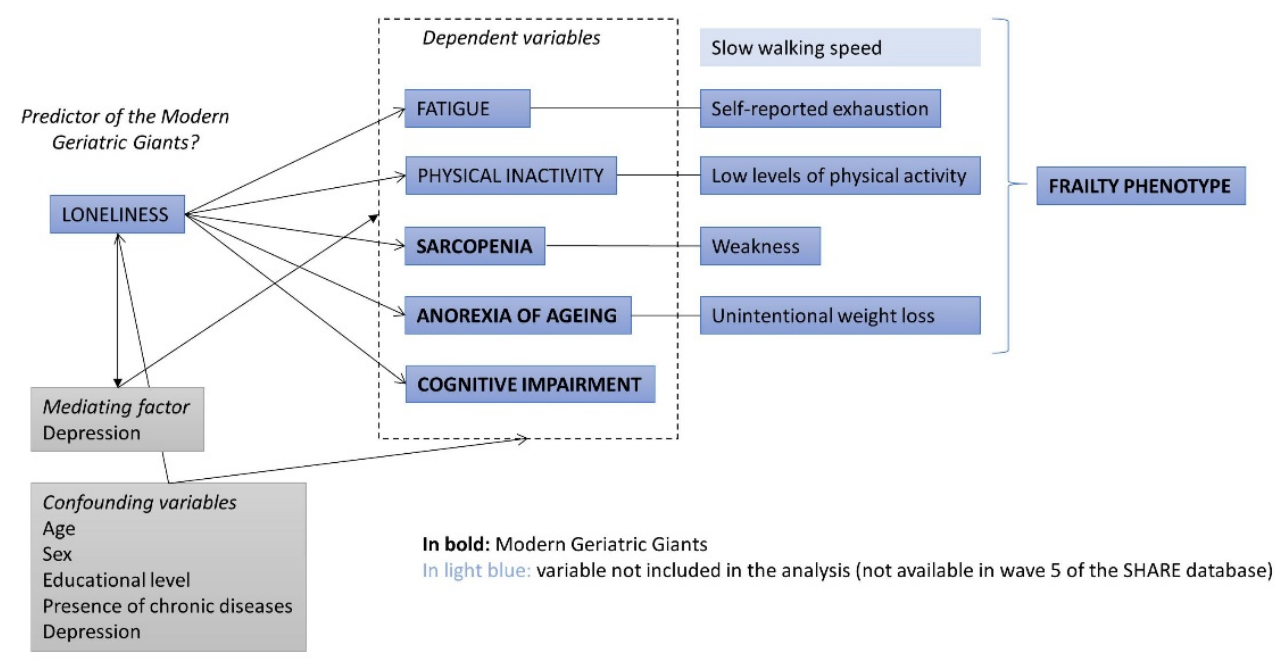




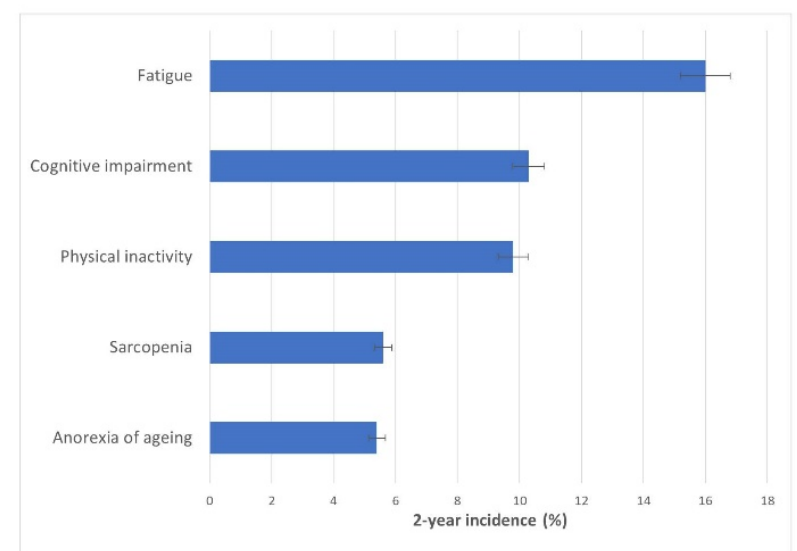




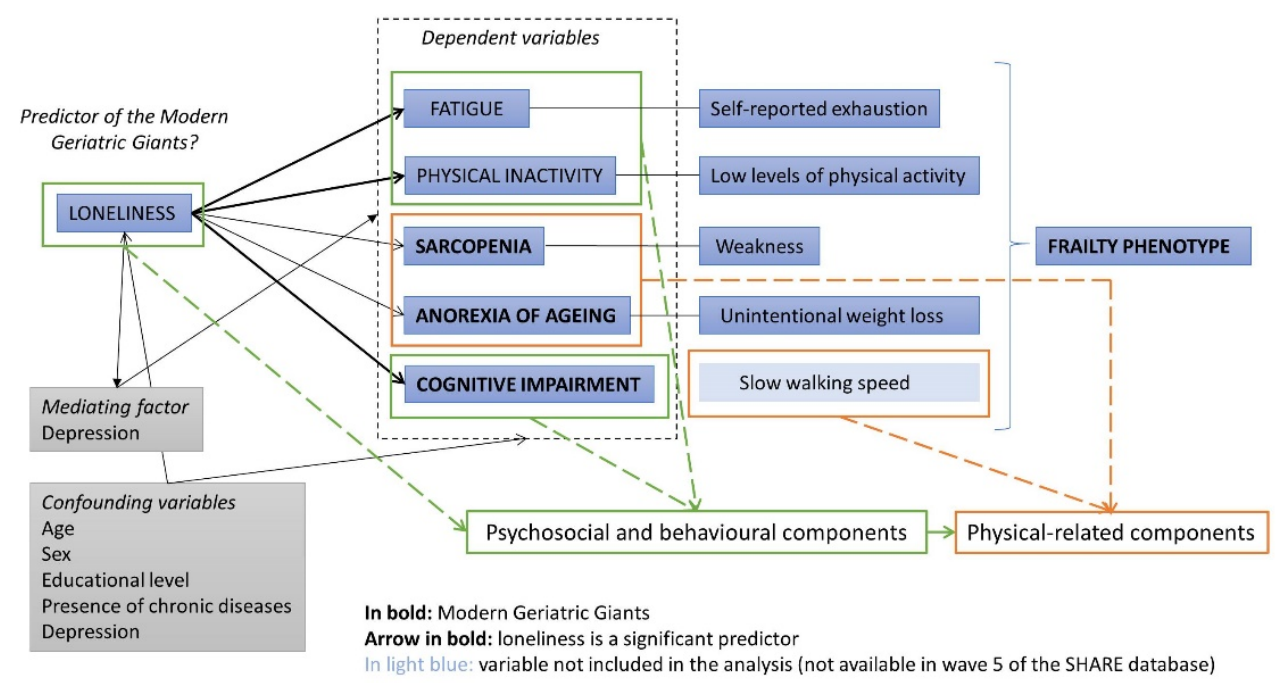


Table 1. Descriptive analysis of the subsamples (according to reported loneliness) for the outcomes fatigue, physical inactivity, sarcopenia, anorexia of ageing, and cognitive impairment in older adults.

\begin{tabular}{|c|c|c|}
\hline Characteristics & & \\
\hline Fatigue $(n=20237)$ & Yes & No \\
\hline \multicolumn{3}{|l|}{ Sex, n (\%) } \\
\hline Men & $1289(13.6)$ & $8188(86.4)$ \\
\hline Women & $1950(18.1)$ & $8810(81.9)$ \\
\hline Age, M (DE) & 75.35 (6.97) & $73.12(6.44)$ \\
\hline Chronic diseases, M (DE) & $2.34(1.60)$ & $1.75(1.42)$ \\
\hline Education, M (DE) & $2.70(1.43)$ & $2.92(1.43)$ \\
\hline \multicolumn{3}{|l|}{ Region, $\mathrm{n}(\%)$} \\
\hline Northern & $230(7.2)$ & $2964(92.8)$ \\
\hline Central & $1184(15.6)$ & $6418(84.4)$ \\
\hline Eastern & $1096(23.1)$ & 3656 (76.9) \\
\hline Southern & $3239(16.0)$ & $16998(84.0)$ \\
\hline Israel & $122(19.9)$ & $490(80.1)$ \\
\hline \multicolumn{3}{|l|}{ Depression, $\mathrm{n}(\%)$} \\
\hline No & $2022(12.8)$ & $13782(87,2)$ \\
\hline Yes & 1099 (27.7) & $2865(72.3)$ \\
\hline \multicolumn{3}{|l|}{ Loneliness, n (\%) } \\
\hline No & $2633(14.6)$ & $15370(85.4)$ \\
\hline Yes & $527(27.4)$ & $1394(72.6)$ \\
\hline Physical inactivity ( $n=17742)$ & Yes & No \\
\hline \multicolumn{3}{|l|}{ Sex, $n(\%)$} \\
\hline Men & $693(8.3)$ & $7656(91.7)$ \\
\hline Women & $1060(11.3)$ & $8333(88.7)$ \\
\hline Age & $77.2(7.3)$ & $72.8(6.1)$ \\
\hline Chronic diseases & $2.6(1.7)$ & $1.9(1.5)$ \\
\hline Education & $2.3(1.3)$ & $2.9(1.5)$ \\
\hline \multicolumn{3}{|l|}{ Region, n (\%) } \\
\hline Northern & $163(4.5)$ & $3450(95.5)$ \\
\hline Central & $688(8.6)$ & $7298(91.4)$ \\
\hline Eastern & $200(9.2)$ & $1975(90.8)$ \\
\hline Southern & 702 (17.7) & $3266(82.3)$ \\
\hline \multicolumn{3}{|l|}{ Depression, n (\%) } \\
\hline No & $1063(7.8)$ & 12615 (92.2) \\
\hline Yes & $631(16.7)$ & $3156(83.3)$ \\
\hline \multicolumn{3}{|l|}{ Loneliness, n (\%) } \\
\hline No & $1401(8.8)$ & 14495 (91.2) \\
\hline Yes & $301(18.1)$ & 1366 (81.9) \\
\hline Sarcopenia (n=20098) & Yes & No \\
\hline \multicolumn{3}{|l|}{ Gender, n (\%) } \\
\hline Men & $541(5.8)$ & $8739(94.2)$ \\
\hline Women & $592(5.5)$ & 10226 (94.5) \\
\hline Age, M (DE) & $78.2(7.0)$ & $75.6(5.9)$ \\
\hline Chronic diseases, M (DE) & $2.4(1.7)$ & $1.9(1.5)$ \\
\hline Education, M (DE) & $2.5(1.4)$ & $3.0(1.4)$ \\
\hline \multicolumn{3}{|l|}{ Region, n (\%) } \\
\hline Northern & $139(4.0)$ & 3319 (96.0) \\
\hline
\end{tabular}




\begin{tabular}{|c|c|c|}
\hline Central & $346(4.4)$ & $7573(95.6)$ \\
\hline Eastern & $255(5.1)$ & 4778 (94.9) \\
\hline Southern & $331(10.5)$ & $2810(89.5)$ \\
\hline Israel & $62(11.3)$ & $485(88.7)$ \\
\hline \multicolumn{3}{|l|}{ Depression, n (\%) } \\
\hline No & 729 (4.7) & $14684(95.3)$ \\
\hline Yes & $380(8.5)$ & $4090(91.5)$ \\
\hline \multicolumn{3}{|l|}{ Loneliness, n (\%) } \\
\hline No & $943(5.2)$ & 17096 (94.8) \\
\hline Yes & $182(9.2)$ & $1804(90.8)$ \\
\hline Anorexia of ageing ( $n=24524)$ & Yes & No \\
\hline \multicolumn{3}{|l|}{ Gender, n (\%) } \\
\hline Men & $562(5.1)$ & $10413(94.9)$ \\
\hline Women & $759(5.6)$ & $12790(94.4)$ \\
\hline Age, $M$ (DE) & $75.5(7.1)$ & $73.7(6.7)$ \\
\hline Chronic diseases, M (DE) & $2.6(1.8)$ & $2.0(1.5)$ \\
\hline Education, M (DE) & $1.2(2.6)$ & $2.9(1.4)$ \\
\hline \multicolumn{3}{|l|}{ Region, $\mathrm{n}(\%)$} \\
\hline Northern & $159(4.3)$ & $3503(95.7)$ \\
\hline Central & $498(5.5)$ & $8548(94.5)$ \\
\hline Eastern & $379(6.3)$ & $5676(93.7)$ \\
\hline Southern & $232(4.8)$ & $4566(95.2)$ \\
\hline Israel & $53(5.5)$ & $910(94.5)$ \\
\hline \multicolumn{3}{|l|}{ Depression, n (\%) } \\
\hline No & 454 (4.5) & 16935 (95.5) \\
\hline Yes & $792(7.4)$ & 5664 (92.6) \\
\hline \multicolumn{3}{|l|}{ Loneliness, n (\%) } \\
\hline No & $1051(4.5)$ & $20046(95.5)$ \\
\hline Yes & $214(7.4)$ & $2745(92.6)$ \\
\hline Cognitive impairment ( $n=18328)$ & Yes & No \\
\hline \multicolumn{3}{|l|}{ Gender, n (\%) } \\
\hline Men & $862(10.0)$ & $7792(90.0)$ \\
\hline Women & $1038(10.7)$ & $8636(89.3)$ \\
\hline Age & $75.2(6.8)$ & $72.6(6.2)$ \\
\hline Chronic diseases & $2.3(1.7)$ & $2.0(1.6)$ \\
\hline Education & $2.4(1.4)$ & $3.1(1.4)$ \\
\hline \multicolumn{3}{|l|}{ Region, n (\%) } \\
\hline Northern & $239(5.8)$ & $3867(94.2)$ \\
\hline Central & $835(9.2)$ & $8252(90.8)$ \\
\hline Eastern & $213(8.4)$ & $2327(91.6)$ \\
\hline Southern & $613(23.6)$ & $1982(76.4)$ \\
\hline \multicolumn{3}{|l|}{ Depression, n (\%) } \\
\hline No & $1329(9.3)$ & 13019 (90.7) \\
\hline Yes & $551(14.4)$ & $3281(85.6)$ \\
\hline \multicolumn{3}{|l|}{ Loneliness, n (\%) } \\
\hline No & $1640(9.9)$ & $14954(90.1)$ \\
\hline Yes & $255(15.1)$ & 1429 (84.9) \\
\hline
\end{tabular}


Table 2. Final multivariate models of loneliness as a predictor of the outcomes fatigue, physical inactivity, sarcopenia, anorexia of ageing and cognitive impairment in older adults.

\begin{tabular}{|c|c|c|c|c|}
\hline & $\mathrm{RR}(95 \% \mathrm{Cl})$ & $p$ value & Adjusted RR $(95 \% \mathrm{Cl})$ & $p$ value \\
\hline \multicolumn{5}{|l|}{ Fatigue } \\
\hline Age & $1.04(1.04-1.05)$ & $<0.001$ & $1.03(1.02-1.04)$ & $<0.001$ \\
\hline \multicolumn{5}{|l|}{ Gender } \\
\hline Men & 1 & & 1 & \\
\hline Women & $1.33(1.24-1.43)$ & $<0.001$ & $1.12(1.04-1.21)$ & 0.004 \\
\hline Chronic diseases & $1.22(1.19-1.24)$ & $<0.001$ & $1.15(1.13-1.18)$ & $<0.001$ \\
\hline Education & $0.92(0.89-0.94)$ & $<0.001$ & $0.95(0.92-0.98)$ & $<0.001$ \\
\hline \multicolumn{5}{|l|}{ Region } \\
\hline Northern & 1 & & & \\
\hline Central & $2.16(1.88-2.49)$ & $<0.001$ & $1.96(1.70-2.26)$ & $<0.001$ \\
\hline Eastern & $3.20(2.78-3.69)$ & $<0.001$ & $2.70(2.33-3.12)$ & $<0.001$ \\
\hline Southern & $2.07(1.78-2.41)$ & $<0.001$ & $1.42(1.20-1.68)$ & $<0.001$ \\
\hline Israel & $2.77(2.22-3.45)$ & $<0.001$ & $2.24(1.75-2.87)$ & $<0.001$ \\
\hline \multicolumn{5}{|l|}{ Depression } \\
\hline No & 1 & & 1 & \\
\hline Yes & $2.17(2.01-2.33)$ & $<0.001$ & $1.67(1.53-1.81)$ & $<0.001$ \\
\hline \multicolumn{5}{|l|}{ Loneliness } \\
\hline No & 1 & & 1 & \\
\hline Yes & $1.88(1.71-2.06)$ & $<0.001$ & $1.30(1.17-1.45)$ & $<0.001$ \\
\hline \multicolumn{5}{|l|}{ Physical inactivity } \\
\hline Age & $1.09(1.08-1.09)$ & $<0.001$ & 1.08 (1.07-1.09) & $<0.001$ \\
\hline \multicolumn{5}{|l|}{ Gender } \\
\hline Men & 1 & & 1 & \\
\hline Women & $1.36(1.24-1.50)$ & $<0.001$ & $1.18(1.06-1.32)$ & 0.003 \\
\hline Chronic diseases & $1.25(1.22-1.28)$ & $<0.001$ & $1.17(1.13-1.21)$ & $<0.001$ \\
\hline Education & $0.73(0.71-0.76)$ & $<0.001$ & $0.86(0.83-0.90)$ & $<0.001$ \\
\hline \multicolumn{5}{|l|}{ Region } \\
\hline Northern & 1 & & 1 & \\
\hline Central & $1.91(1.61-2.27)$ & $<0.001$ & $1.86(1.56-2.23)$ & $<0.001$ \\
\hline Eastern & $2.04(1.66-2.51)$ & $<0.001$ & $2.04(1.65-2.54)$ & $<0.001$ \\
\hline Southern & $3.92(3.31-4.65)$ & $<0.001$ & $3.04(2.51-3.67)$ & $<0.001$ \\
\hline \multicolumn{5}{|l|}{ Depression } \\
\hline No & 1 & & & \\
\hline Yes & $2.14(1.94-2.37)$ & $<0.001$ & $1.39(1.23-1.56)$ & $<0.001$ \\
\hline \multicolumn{5}{|l|}{ Loneliness } \\
\hline No & 1 & & 1 & \\
\hline Yes & $2.05(1.81-2.32)$ & $<0.001$ & $1.24(1.07-1.43)$ & 0.004 \\
\hline \multicolumn{5}{|l|}{ Sarcopenia } \\
\hline Age & $1.12(1.11-1.13)$ & $<0.001$ & $1.12(1.11-1.13)$ & $<0.001$ \\
\hline \multicolumn{5}{|l|}{ Gender } \\
\hline Men & 1 & & & \\
\hline Women & $0.94(0.84-1.05)$ & 0.287 & $0.86(0.75-0.98)$ & 0.023 \\
\hline Chronic diseases & $1.20(1.16-1.24)$ & $<0.001$ & $1.11(1.07-1.16)$ & $<0.001$ \\
\hline Education & $0.80(0.76-0.84)$ & $<0.001$ & $0.92(0.88-0.97)$ & 0.001 \\
\hline \multicolumn{5}{|l|}{ Region } \\
\hline Northern & 1 & & 1 & \\
\hline Central & $1.09(0.89-1.32)$ & 0.406 & $1.06(0.86-1.30)$ & 0.573 \\
\hline Eastern & $1.26(1.03-1.55)$ & 0.028 & $1.28(1.03-1.59)$ & 0.024 \\
\hline
\end{tabular}




\begin{tabular}{|c|c|c|c|c|}
\hline Southern & $2.62(2.15-3.20)$ & $<0.001$ & $2.38(1.91-2.98)$ & $<0.001$ \\
\hline Israel & $2.82(2.09-3.80)$ & $<0.001$ & $3.13(2.24-4.39)$ & $<0.001$ \\
\hline \multicolumn{5}{|l|}{ Depression } \\
\hline No & 1 & & & \\
\hline Yes & $1.80(1.59-2.03)$ & $<0.001$ & $1.40(1.22-1.61)$ & $<0.001$ \\
\hline \multicolumn{5}{|l|}{ Loneliness } \\
\hline No & 1 & & - & - \\
\hline Yes & $1.75(1.50-2.05)$ & $<0.001$ & - & - \\
\hline \multicolumn{5}{|c|}{ Anorexia of ageing } \\
\hline Age & $1.03(1.02-1.04)$ & $<0.001$ & $1.02(1.01-1.03)$ & $<0.001$ \\
\hline \multicolumn{5}{|l|}{ Gender } \\
\hline Men & 1 & & 1 & \\
\hline Women & $1.09(0.98-1.22)$ & 0.107 & $0.97(0.86-1.10)$ & 0.645 \\
\hline Chronic diseases & $1.22(1.19-1.26)$ & $<0.001$ & $1.16(1.12-1.20)$ & $<0.001$ \\
\hline Education & $0.90(0.86-0.94)$ & $<0.001$ & $0.91(0.87-0.95)$ & $<0.001$ \\
\hline \multicolumn{5}{|l|}{ Region } \\
\hline Northern & 1 & & 1 & \\
\hline Central & $1.27(1.06-1.52)$ & 0.009 & $1.17(0.97-1.40)$ & 0.104 \\
\hline Eastern & $1.44(1.20-1.73)$ & $<0.001$ & $1.27(1.05-1.54)$ & 0.015 \\
\hline Southern & $1.11(0.91-1.36)$ & 0.296 & $0.75(0.59-0.95)$ & 0.017 \\
\hline Israel & $1.27(0.93-1.73)$ & 0.135 & $0.93(0.65-1.35)$ & 0.721 \\
\hline \multicolumn{5}{|l|}{ Depression } \\
\hline No & 1 & & 1 & \\
\hline Yes & $1.66(1.48-1.86)$ & $<0.001$ & $1.41(1.23-1.60)$ & $<0.001$ \\
\hline \multicolumn{5}{|l|}{ Loneliness } \\
\hline No & 1 & & - & - \\
\hline Yes & $1.45(1.25-1.68)$ & $<0.001$ & - & . \\
\hline \multicolumn{5}{|c|}{ Cognitive impairment } \\
\hline Age & $1.05(1.04-1.06)$ & $<0.001$ & $1.05(1.05-1.06)$ & $<0.001$ \\
\hline \multicolumn{5}{|l|}{ Gender } \\
\hline Men & 1 & & 1 & \\
\hline Women & $1.05(0.96-1.15)$ & 0.268 & $0.94(0.85-1.04)$ & 0.247 \\
\hline Chronic diseases & $1.10(1.07-1.13)$ & $<0.001$ & $1.05(1.02-1.08)$ & 0.003 \\
\hline Education & $0.73(0.70-0.75)$ & $<0.001$ & $0.80(0.77-0.84)$ & $<0.001$ \\
\hline \multicolumn{5}{|l|}{ Region } \\
\hline Northern & 1 & & 1 & \\
\hline Central & $1.58(1.37-1.82)$ & $<0.001$ & 1.61 (1.39-1.87) & $<0.001$ \\
\hline Eastern & $1.44(1.20-1.73)$ & $<0.001$ & $1.36(1.12-1.65)$ & 0.002 \\
\hline Southern & $4.06(3.49-4.71)$ & $<0.001$ & $3.18(2.70-3.75)$ & $<0.001$ \\
\hline \multicolumn{5}{|l|}{ Depression } \\
\hline No & 1 & & 1 & \\
\hline Yes & $1.55(1.41-1.71)$ & $<0.001$ & $1.31(1.16-1.47)$ & $<0.001$ \\
\hline \multicolumn{5}{|l|}{ Loneliness } \\
\hline No & 1 & & 1 & \\
\hline Yes & $1.53(1.34-1.75)$ & $<0.001$ & $1.26(1.09-1.46)$ & 0.002 \\
\hline
\end{tabular}

